\title{
IDEOLOGÍA Y PODER EN LOS DISCURSOS MUSEOGRÁFICOS: LA CREACIÓN DE «SALAS DE GOYA» EN LOS MUSEOS ESPAÑOLES
}

(1875-1915)

\section{IDEOlOgy AND Power in Museum Displays: THE Creation of «Goya's Rooms» in Spanish Museums (1875-1915)}

\author{
Guillermo Juberías Gracia
}

Universidad de Zaragoza

Resumen: En la España de finales del siglo xix, la figura de Goya vivió un proceso de recuperación orquestado desde las instituciones públicas. Un ingrediente fundamental fue la creación de salas dedicadas al artista de manera monográfica en los museos españoles. A través de este estudio se arrojan datos inéditos sobre la creación de «salas de Goya»: en el Museo del Prado, el Museo de Bellas Artes de Valencia y el antiguo Museo Provincial de Zaragoza. Se ofrece una visión general de las motivaciones que llevaron a la creación de estos espacios y su trascendencia en la canonización del maestro aragonés.

Palabras clave: museografía, identidad nacional, Goya, salas de Goya.

AbSTRACT: In the late nineteenth century in Spain, the figure of Goya lived a process of recovery orchestrated from public institutions. A fundamental ingredient was the creation of rooms dedicated to the artist 
in a monographic way in Spanish museums. Through this study, new data about the creation of «Goya's rooms» are presented: in the Prado Museum, the Museum of Fine Arts of Valencia and the old Provincial Museum of Zaragoza. It offers an overview of the motivations that led to the creation of these spaces and their importance in the canonization of the Aragonese master.

Key words: Museography, national identity, Goya, Goya's rooms.

\section{INTRODUCCIÓN}

Tradicionalmente, el siglo XIX se ha visto como un periodo liberalizador para las creaciones culturales por la pérdida de poder de los antiguos estamentos privilegiados y la consolidación de la burguesía como la nueva clientela artística. Sin embargo, esta circunstancia no implicó una mayor independencia para las obras de arte, que siguieron sometidas a los discursos del poder político y las nuevas clases sociales. Durante la segunda mitad de la centuria se llevó a su apogeo el proceso de construcción de la identidad nacional de España, llegando a convertirse en una obsesión en la política y la cultura estatal, culminando con los ideales de la Generación del 98. ${ }^{1}$ Este largo camino llevaría a la creación de un canon artístico español, fenómeno que tuvo su parangón en otras manifestaciones como la música y la literatura. ${ }^{2}$ En el ámbito de la pintura, uno de los primeros pasos fue la creación por Real Decreto en 1853 de las Exposiciones Nacionales de Bellas Artes. El preámbulo de dicha ley ponía de manifiesto su deseo de resaltar «la importancia social del arte, su peso en el patriotismo, su capacidad didáctica, ser fórmula por y para el progreso».

En la génesis de este constructo, las instituciones prestaron especial atención al arte de los maestros nacionales, propuesto como espejo para las nuevas generaciones de artistas y para la sociedad en general. De todos ellos, la pintura de Francisco de Goya (1746-1828) resultaba especialmente útil para expresar los ideales del nuevo estado liberal. La musealización de sus obras

1. Una parte de este estudio es resultado de una estancia de investigación llevada a cabo en el Instituto de Historia del CSIC, entre marzo y abril de 2019, bajo la dirección de IDoia Murga CAstro, financiada dentro del Programa de Estancias de Investigación CAI-Ibercaja. N. ${ }^{\circ}$ de referencia: CH 22/18. Grupo de investigación consolidado «Observatorio Aragonés de Arte en la Esfera Pública» financiado con fondos FEDER y Gobierno de Aragón.

2. Dicha cuestión ha atraído la atención de historiadores del arte como Francisco Calvo Serraller o Jesusa Vega. Dos obras de referencia para el estudio de la construcción de una escuela pictórica española durante el siglo Xix serían: Francisco Calvo Serraller: La invención del arte español, Galaxia Gutenberg, Madrid, 2013, y Jesusa Vega González: Pasado y Tradición. La construcción visual del imaginario español en el siglo XIX, Editorial Polifemo, Madrid, 2016. También aporta un interesante panorama histórico la obra de: Ignacio Peiró Martín: En los altares de la patria. La construcción de la cultura nacional española, Akal, Madrid, 2017. Peiró llevó a cabo un análisis de las diferentes esferas - política, social, artística, científica- que promovieron la construcción de la identidad nacional española desde finales del siglo XVIII hasta 1936. 
ofreció una lectura muy concreta sobre un periodo histórico convulso: el reinado de Carlos IV (1788-1808) y la guerra de la Independencia (1808-1814), momentos que interesaba releer en clave nacional, eliminando las facetas más contestarías de la obra del maestro aragonés.

En este sentido, resulta interesante analizar el contexto de creación de las salas dedicadas de forma monográfica al artista en varios museos españoles: el Prado, el Museo de Bellas Artes de Valencia y el Museo de Zaragoza. Constituyen tres ejemplos en los que, con propósitos distintos, se privilegió la obra del pintor aragonés sobre la de otros artistas representados en las colecciones.

\section{Las salas de Goya en el Museo del Prado}

De todos los museos españoles, el Museo del Prado fue el que desempeñó un papel más sustancial en la configuración de ese canon artístico nacional a través de su discurso museográfico. En este sentido, es interesante apreciar cómo la primera sala dedicada monográficamente a un artista fue la llamada «sala de Goya», destinada a la exposición de los cartones para tapices pintados por el maestro aragonés. ${ }^{3}$

Durante la segunda mitad del XIX, el Museo del Prado estuvo dirigido por consagrados pintores que, en sintonía con los vaivenes de la atmósfera política, fueron modificando su discurso museográfico. Tras el breve mandato de Juan Antonio Rivera (1857-1860), le sucederían Federico de Madrazo (1860-1869 y 1881-1894), Francisco Sans y Cabot (1873-1881), Vicente Palmaroli (18951896), Franciso Pradilla (1896-1898) y Luis Álvarez Catalá (1898-1901). Tras su último periodo como museo real durante el reinado de Isabel II, la revolución liberal de 1868 permitió al Prado, en palabras de Javier Portús, emprender un camino hacia su nacionalización. ${ }^{4}$ Dicho proceso tuvo comienzo en febrero de ese mismo año con la conversión del patrimonio real en bienes de la nación.

La obra de Goya desempeñó un papel importante en esta evolución del Museo. De los artistas españoles fallecidos entrado el xix, Goya era a mediados

3. En el artículo no se pretende llevar a cabo un análisis pormenorizado de la llegada de obras de Goya al Museo del Prado. A modo de antecedente, hay que señalar cómo en el momento de la apertura del Museo Nacional de Pintura y Escultura en 1819, solamente se expusieron los retratos ecuestres de Carlos IV y de María Luisa de Parma, además de El picador. Goya ocupó la tercera sala de las dedicadas a pintura española, junto con otros artistas vivos como Aparicio o José de Madrazo y otros ya fallecidos como Bayeu y Maella. PEDRO Beroqui Martínez: El Museo del Prado (Notas para su historia), Gráficas Marinas, Madrid, 1933, p. 102. La familia de Carlos IV ingresó posiblemente en 1828. Fue destinado al Gabinete de Descanso del Museo, un espacio privado para los monarcas: PIERre GÉAL: «El salón de la Reina Isabel en el Museo del Prado (1853-1899)», en Boletín del Museo del Prado, Museo Nacional del Prado, Madrid, 2001, pp. 143-172. Sin embargo, pasaron décadas hasta que llegó a ser expuesto al público, hacia 1867-1872. En este gabinete de descanso también se encontraban los retratos ecuestres de la reina María Luisa y de Carlos IV, además de un boceto del retrato de la infanta María Josefa para La familia de Carlos IV: Charles Yriarte: Goya, H. Plon, París, 1867, p. 131.

4. Javier Portús PÉrez: «La nacionalización del Prado, 1868-1898. Un museo para los pintores», en vv. AA.: Museo del Prado: 1819-2019. Un lugar de memoria, Museo Nacional del Prado, Madrid, 2018, pp. 70-107. 
de la centuria el que gozaba de mayor fortuna crítica, tanto entre los visitantes extranjeros que llegaban al museo como entre los locales. Por ello, la disposición de sus obras en las salas fue seguida de cerca por parte de los directores de la institución. José y Federico de Madrazo jugaron al respecto un papel crucial debido a su vinculación a los círculos cortesanos del periodo isabelino y de la Restauración. Por este motivo, dirigieron sus esfuerzos a privilegiar el Goya retratista y pintor de género, frente a otras facetas más críticas con la sociedad de su tiempo presentes en la colección.

Prueba de ello fue la deriva de sus obras por diferentes espacios del museo, hasta la construcción de las dos salas monográficas que son objeto de esta investigación. Al respecto, es interesante apreciar el emplazamiento de los célebres lienzos que representaban escenas del dos y del tres de mayo en Madrid: La lucha con los mamelucos y Los fusilamientos, pinturas que llegaron al museo antes de 1834, momento en el que se describen en «el almacén grande». En 1854, un breve artículo anónimo publicado en el diario La Nación, acusaba al director del museo, José de Madrazo, de tenerlos mal expuestos: ${ }^{5}$

No sabemos por qué motivo los cuadros del Dos de Mayo del célebre pintor Goya no salen de la oscura cárcel a que los tiene condonados el actual director del Museo de pinturas. Dichos cuadros que debían ser uno de los más ricos ornamentos de la escuela española, yacen arrinconados en una de las más oscuras galerías de dicho Museo.

Sin embargo, cuando esta breve nota fue publicada, no debió de complacer a José de Madrazo, quien unos días más tarde contestaba en el mismo periódico: ${ }^{6}$

... diré que el motivo de haberlos dejado en el mismo sitio, es cabalmente porque me intereso cuanto el que más en la buena forma de tan esclarecido pintor. Dichos cuadros del Dos de Mayo no son seguramente los que han inmortalizado su nombre, ni deben considerarse más que como unos bosquejos hechos de pura práctica; por lo que se hallan muy distantes de aquel mérito artístico que tanto le distingue en otras muchas obras que ejecutó con gloria. Sin salir del expresado Real Museo, lo están así atestiguando los admirables retratos ecuestres del tamaño natural de los reyes Carlos IV y su augusta esposa, que se hallan perfectamente colocados o iluminados, con otro pequeño muy precioso de un picador a caballo.

El canon estético cambió rápido y pocos años más tarde, Charles Yriarte en su obra sobre Goya en 1867, reveló la presencia de ambos cuadros y de bocetos de La familia de Carlos IV en la galería central del museo, ubicación cuidadosamente elegida, como explico más adelante. ${ }^{7}$

5. La Nación, 24 de noviembre de 1854, p. 3. Recogido en: GÉAL, «El salón de la Reina Isabel...», pp. 143-172.

6. La Nación, 01 de diciembre de 1854, p. 4.

7. YRIARTE, Goya, pp. 130-131. 
Tal y como apuntan Jesusa Vega y Julián Vidal, las dos principales vías de llegada de obras de Goya al Prado durante el xix fueron la colección real y los recibidos del Museo de la Trinidad. ${ }^{8}$ Su subdirector a partir de 1862 fue Gregorio Cruzada Villaamil, quien desempeñó un papel fundamental en la política de adquisiciones estatales. ${ }^{9}$ Tras el traspaso de las obras del Museo de la Trinidad al Prado en 1872, los goyas procedentes del primero se ubicaron en el salón de contemporáneos españoles..$^{10} \mathrm{El}$ Museo del Prado conserva un inventario topográfico manuscrito, fechado hacia 1874 en el que se señalaban las ubicaciones de estas pinturas. Obras de Goya podían contemplarse en la sala de descanso (La familia de Carlos IV, entre otras), ${ }^{11}$ y también en los pasillos bajos de Levante y Poniente. ${ }^{12}$

Durante los años setenta y ochenta del siglo XIX, las dos incorporaciones más destacables de goyas al Museo, fueron la llegada en 1870 de los cartones para tapices y en 1881 la donación de las Pinturas negras.

Entre ambos conjuntos, el primero en ser valorado y ubicado en una sala monográfica fue el de los cartones, expuestos en la conocida como «sala de Goya», creada en 1875. En ese año, el diario El Imparcial se hacía eco de la inauguración de la sala, anunciando que pronto sería abierta al público, ${ }^{13}$ circunstancia que tardaría algunos años en cumplirse tal y como atestiguan los viajeros que visitaban el museo. Pedro de Madrazo, en su catálogo de los cuadros del museo reeditado y ampliado en 1882, dedicó unas páginas a este espacio. ${ }^{14}$ En él se expusieron los cartones para tapices de Goya redescubiertos tras la gloriosa por Cruzada Villaamil en el Palacio Real de Madrid. Pedro de Madrazo especificó que la sala se ubicaba en la segunda planta del museo, un piso que normalmente no se encontraba abierto al público. ${ }^{15}$

Ceferino Araujo en su obra Los museos de España criticó esta sala dedicada a Goya en el Museo del Prado: ${ }^{16}$

8. Jesusa Vega GonzÁlez y Julián Vidal Rivas: «El devenir de la historia del arte, sus prácticas y sus consecuencias: el caso de Francisco de Goya», en Luis Arciniega García (coor.): Memoria y significado: uso y recepción de los vestigios del pasado, Universidad de Valencia, Valencia, 2013, pp. 341-422.

9. En 1866 se adquirieron tres obras de Goya a Román Garreta de Huertas, cuñado de Federico de Madrazo y otra a Andrés Mollinedo, y hasta 1872 se recibieron cinco goyas más procedentes de diversas instituciones nacionales.

10. Pedro de Madrazo: Catálogo de los cuadros del Museo del Prado de Madrid, Museo Nacional del Prado, Madrid, 1873, p. XIII.

11. «Inventario Topográfico de 1874». 1874. Caja: 1374, Legajo: 114.08, № Exp: 1, Cuaderno n. ${ }^{\circ}$ 14, Archivo del Museo del Prado [AMP].

12. «Inventario Topográfico de 1874». 1874. Caja: 1374, Legajo: 114.08, No Exp: 1, Cuaderno n. ${ }^{\circ}$ 19, AMP.

13. El Imparcial, 30 de abril de 1875, p. 3.

14. Pedro de Madrazo: Catálogo de los cuadros del Museo del Prado de Madrid, Museo Nacional del Prado, Madrid, 1882, pp. 435-438.

15. En 1883 consta un proyecto para el entarimado de las salas de Goya y Alfonso XII. El proyecto viene acompañado de un plano de la sala elaborado por el arquitecto Alejandro Sureda en junio de 1883. En él se aprecia que la sala constaba de un único departamento y poseía planta rectangular. AlEJANDro SUREDA Chappron, «Plano N. ${ }^{\circ}$ 2. Entarimado de la sala de Goya». 1883. Caja: 412, Legajo: 34.08, n. ${ }^{\circ}$ Exp: 11. AMP.

16. Ceferino Araujo SÁnchez: Los Museos de España, Imprenta de Medina y Navarro, Madrid, 1875, pp. 85 y 86 . 


\begin{abstract}
A pesar de tener Goya cierta importancia como pintor [...], no creo del todo necesario llenar una sala casi exclusivamente con sus obras, distinción que nunca se ha pensado hacer con otro pintor, teniendo número suficiente de composiciones de Rubens, Ticiano o de Velázquez para haber dedicado a cualquiera de ellos esta especie de apoteosis [...]. Los cartones para tapices del Pardo y del Escorial, mejor estarían adornando los palacios de los sitios reales, que en el Museo.
\end{abstract}

Araujo, quien años después publicaría la obra Goya y su época, ${ }^{17}$ parecía no apreciar demasiado su pintura, negando en ella la genialidad de las obras de los maestros históricos del arte español y europeo.

Una opinión distinta fue expresada por la crítica francesa, que alabó la decisión de crear una sala monográfica para el maestro aragonés. El historiador y escritor francés François-Victor Fournel la citó en su libro Aux pays du soleil. Un été en Espagne, editado en 1883. Afirmó que se trataba de un nuevo espacio creado en el museo, en el que las obras del pintor de Fuendetodos se mostraban con especial acierto, en abundancia. Las pinturas que más destacó son los cuadros de género «que ponen en escena las costumbres, los trajes, los usos y los divertimentos de España». Señaló que la sala se encontraba apartada y cerrada siempre, y que su existencia solamente era revelada al visitante por los guardianes del museo, quienes a cambio de una propina se turnaban enseñándola. ${ }^{18}$

Diez años más tarde, en el Bulletin de l'année de 1893 de la Société Normande de Géographie, era publicado un artículo titulado «Deux mois en Espagne et en Andalousie». En él se anunciaba que la sala de Goya había sido recientemente abierta al público y de nuevo se alababa dicho espacio. Para el autor del artículo, el periodista marsellés Gaston Routier, se trataba de la mejor sala para el estudio del «arte castellano»y Goya era el verdadero «pintor nacional» de España. ${ }^{19}$

Entre los testimonios españoles sobre la sala de Goya, destaca el del padre de José Ortega y Gasset, el escritor José Ortega Munilla, en El Imparcial, diario que llegó a dirigir. Se trata de un interesante artículo en el que constató el creciente interés que Goya suscitaba en España, haciéndose eco de cómo el Museo del Prado iba incrementando su colección de obras del pintor. ${ }^{20}$ Otro de los aspectos problemáticos confirmados por este autor era la dispersión de los tapices goyescos por los palacios españoles, por lo que elogió la decisión de preservar la serie completa de los cartones en una misma sala:

Han sido reunidos en una sala del Museo y dispuestos en convenientes condiciones de luz para que los artistas puedan admirarlos. El primer interés que

17. Ceferino Araujo Sánchez: Goya y su época, La España Moderna, Madrid, 1896.

18. François-Victor Fournel: Aux pays du soleil. Un été en Espagne. A travers l'Italie. Alexandrie et le Caire, A. Mame et fils, Tours, 1883, p. 54

19. Bulletin de l’année de 1893 de la Société Normande de Géographie, 1893, p. 371.

20. El Imparcial, 09 de mayo de 1887, p. 3. 
ofrece esta Exposición en conjunto de los lienzos pintados por Goya para los tapices, es que como estos últimos andan desperdigados por todos los palacios de España, es imposible apreciar en conjunto y en una misma sección el total de la obra, mientras que en el Museo se tiene en un espacio de ochenta metros cuadrados la serie completa de los mis mismos lienzos que pintó la sabia e inspirada mano de Goya.

Cabe preguntarse qué tratamiento recibieron en aquellos años el resto de las obras de Goya conservadas en el museo. Si la sala monográfica supuso el encumbramiento artístico de los cartones para tapices, la presencia de obras del maestro en la galería central significó su introducción definitiva en el canon artístico nacional. Para su estudio contamos con las fotografías del grafoscopio del museo, que permiten analizar detalladamente todas las obras que formaron parte de esta galería.

En 1863, Federico de Madrazo había contactado con el fotógrafo francés Jean Laurent para reproducir las colecciones del museo mediante la imagen fotográfica. Sobre todo, entre 1879 y 1890, se dedicó a la documentación de las obras, creando catálogos que editó y vendió en Madrid y en París, y que en la actualidad constituyen un testimonio imprescindible para el conocimiento sobre la ordenación de las colecciones durante este periodo histórico. Para este estudio arrojan datos las vistas de la galería central del Prado insertas en el grafoscopio, fechadas entre 1882 y $1883 .{ }^{21} \mathrm{Tal}$ y como permiten apreciar, buena parte de las obras de Goya se encontraban expuestas en la galería central, en concreto cerca de su extremo septentrional, hacia la actual puerta de Goya. Las obras del pintor aragonés se disponían a continuación de las pinturas de la escuela barroca española, aunque con algunos lienzos de Esteve, Vicente López y José de Madrazo a modo de separación. Tras estos aparecía el retrato del pintor Francisco Bayeu de Goya, ${ }^{22}$ sobre el que se disponía la Sagrada familia con San Juan Bautista niño. ${ }^{23}$ Bajo la Asunción de Bayeu se encontraba el célebre Cristo crucificado de Goya, ${ }^{24}$ que quedaba por encima del autorretrato del artista. ${ }^{25}$

21. Se trataba de una suerte de caja de madera, que incluía al interior una fotografía de $30 \mathrm{~cm}$ de alto y $1041,5 \mathrm{~cm}$ de longitud, formada a partir de 72 tomas positivadas en papel albúmina, pegadas sobre tela de algodón. En 1882, el yerno de Jean Laurent, Alfonso Roswag y Nogier, presentó al Conservatorio de Artes de Madrid la patente del invento, y durante los meses siguientes se procedió a la fotografía de la galería central del museo madrileño. Para más información: José Manuel Matilla Rodríguez y Javier Portús PÉrez (eds.): El grafoscopio. Un siglo de miradas al Museo del Prado (1819-1920), Museo Nacional del Prado, Madrid, 2004, cat. n. ${ }^{\circ} 48$.

22. Había sido adquirido a un descendiente de los Bayeu en 1866. Procedente del Museo de la Trinidad. Museo Nacional del Prado: Inventario de Nuevas Adquisiciones, Museo Nacional del Prado, Madrid, 1856 (fecha de inicio), núm. 180.

23. Adquirida a sus propietarios por el Ministerio de Fomento en 1877. La reciente compra también debió de motivar la presencia de este Goya en la galería central del museo. Inventario de nuevas adquisiciones, 439, Museo Nacional del Prado, Madrid, 1856 (fecha de inicio).

24. Desde la basílica de San Francisco el Grande había pasado al Museo de la Trinidad en 1835-1836.

25. Museo Nacional del Prado: Inventario de Nuevas Adquisiciones, 176, Madrid, 1856 (fecha de inicio). 
Tras estos retratos y pinturas religiosas, el siguiente tramo de muro estaba presidido por Los Fusilamientos y La lucha con los mamelucos. ${ }^{26}$ En la parte inferior de esa sección de pared, se disponían los bocetos que Goya hizo para La familia de Carlos IV. Las dos últimas obras de Goya expuestas en la Galería eran el retrato de Leocadia Zorrilla y Un garrochista. ${ }^{27}$ El conjunto quedaba acompañado por dos grandes pinturas de historia de Juan Antonio Ribera, además de las alegorías de las estaciones de José de Madrazo y Ribera (fig. 1).

Es decir, para la galería central del Prado se habían escogido cuidadosamente las facetas del Goya cortesano y retratista, disponiendo Los fusilamientos y La lucha con los mamelucos presidiendo una de las secciones, emparentando estos sucesos de la historia contemporánea nacional con los cuadros de historia neoclásicos pintados por Ribera, uno relativo a la historia romana y otro a la España de los reyes visigodos, recordada como un periodo legendario durante el reinado isabelino. Aun así, no se expusieron en esta galería central ninguna de sus Pinturas negras, ya integradas por aquella fecha en las colecciones del museo.

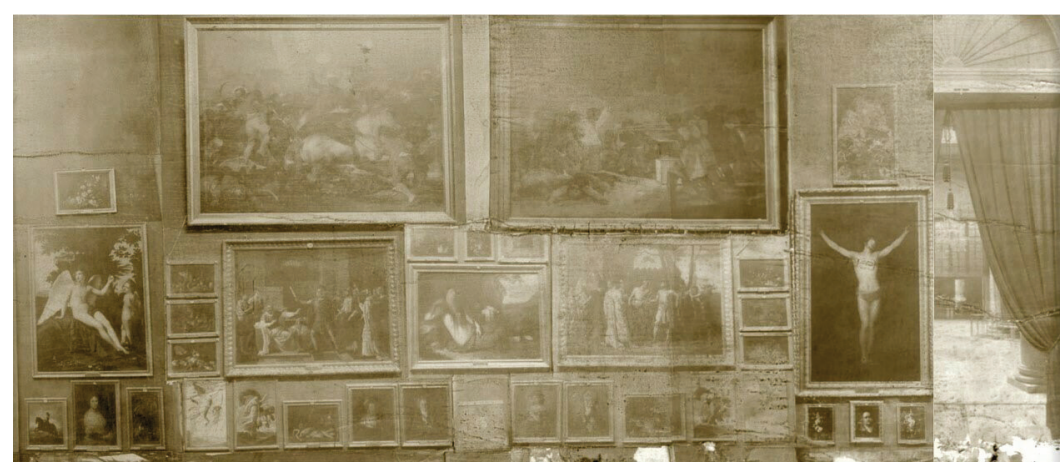

Fig. 1. Alfonso Roswag y Jean Laurent, Galería Central del Museo del Prado, 1882-1883, Museo Nacional del Prado

El siguiente testimonio de la dispersión de los cuadros de Goya en el Prado lo encontramos en un catálogo del museo publicado en Londres en $1896 .{ }^{28}$ En él se incluyen planos de las tres plantas del museo, ubicando la sala de Goya en la superior. Además, también había cuadros del artista en la sala de contemporáneos, en la sala de retratos, salas del noreste, en el pasaje este del sótano y en

26. Ya figuran en el catálogo de 1872 del Museo: Catálogo descriptivo e histórico del Museo del Prado de Madrid, 734, Museo Nacional del Prado, Madrid, 1872, pp. 407-408.

27. La primera adquirida en 1866 por el Museo de la Trinidad y la segunda procedente de las colecciones reales.

28. E. Kerr-Lawson: A catalogue of the paintings in the Museo del Prado at Madrid, William Heinemann London, 1896. 
la rotonda de entrada. En este último espacio, en 1896, estaban expuestas cinco Pinturas negras: Leocadia Zorrilla, La peregrinación a la fuente milagrosa de San Isidro, Asmodea, Las Parcas y El duelo a garrotazos.

La ubicación de cinco de las Pinturas negras en la rotonda de acceso al museo, constituyó un hito en su valoración. Tras su donación al museo en 1881 por el barón d'Erlager, no fueron expuestas hasta 1889. Sin embargo, ya durante los años ochenta del siglo XIX comenzaron a despertar el interés de los eruditos. En 1885, Francisco Fernández de Navarrete, presidente de la Real Academia de Bellas Artes de San Luis de Zaragoza, escribió a Federico de Madrazo solicitándole un informe sobre estas pinturas. ${ }^{29}$ Ante esta demanda, Federico de Madrazo remitió a la Academia zaragozana una copia de las informaciones contenidas en los inventarios del museo y una descripción del retrato del general Palafox. En su contestación quedó patente su valoración positiva hacía el conjunto, considerándolo algo más que mera pintura mural decorativa. ${ }^{30}$

Sin embargo, el proyecto de exponer las catorce Pinturas negras al completo quedó reflejado en 1898 en una memoria sobre una nueva sala de Goya. En el Archivo del Museo del Prado se conserva un documento que contiene la lista de obras que formaban parte de dicho espacio en esa fecha, además de planos, alzados e indicaciones sobre la ubicación de los cuadros en ella. ${ }^{31}$ En esta memoria se ofrece una relación de las pinturas expuestas cuya nómina ascendía a ochenta y tres, además de la planta y el alzado. La sala aparecía dividida en cinco departamentos interconectados, y cada uno de ellos aparecía seccionado a su vez en cuatro letras: A, B, C y D. De la desordenada disposición de los cuadros, la conclusión que podría extraerse es que su localización obedecía a la disposición de sitio en los paramentos (fig. 2). Aun así, puede apreciarse una cierta ordenación temática. El primer y segundo departamento estaba dedicado a los cartones para tapices y a los cuadros de costumbres. El tercer departamento al Goya cortesano y también se introducían algunas de las Pinturas negras: Dos viejos (letra A), El duelo a garrotazos y La peregrinación a la fuente de San Isidro (letra D). En el cuarto departamento se expondrían La lucha con los mamelucos y Los fusilamientos, además de numerosos retratos de corte y de La familia de Carlos IV. La letra C del cuarto y del quinto departamento estaría ocupada por las Pinturas negras, quedando otro espacio más en este departamento para los cartones para tapices.

29. Francisco Fernández de Navarrete: «Solicitud de informe sobre las pinturas murales de Francisco de Goya». 1885. Caja: 357, Legajo: 11.202, No Exp: 28. AMP.

30. Federico de Madrazo y Kuntz: «Minuta de oficio de Federico de Madrazo por el que se informa sobre lo solicitado y remite copia de las anotaciones que constan en los inventarios». 1885. Caja: 357, Legajo: 11.202, N. ${ }^{\circ}$ Exp: 28. AMP.

31. «Relación de los cuadros existentes en la Sala de Goya, planta y alzado de la misma y distribución de obras en sala». 1898. Caja: 1375, Legajo: 114.09, N. ${ }^{\circ}$ Exp: 4. AMP. Los planos fueron publicados en: José Manuel Matilla y Javier Portús Pérez: «Ni una pulgada de pared sin cubrir. La ordenación de las colecciones en el Museo del Prado, 1819-1920», en Matilla y Portús (eds.), El grafoscopio..., p. 83. Los autores expresaron el desorden de la sala, que atendía a la necesidad de cubrir el máximo espacio posible. 


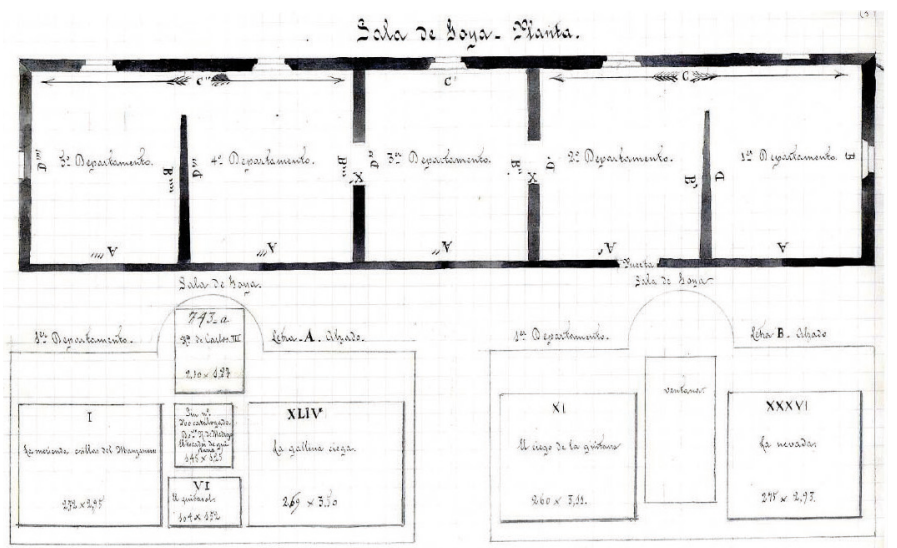

Fig. 2. Sala de Goya, Planta, 2 de febrero de 1898, Archivo del Museo del Prado, caja: 1375 , legajo: 114.09, n. $^{\circ}$ exp: 4.

La datación de este documento en 1898 coincide con un punto de inflexión en la consideración de Goya por parte de académicos, conservadores, escritores y artistas españoles. Si durante el siglo xix fue Velázquez el principal referente entre los maestros históricos españoles, a partir del Desastre del 98, Goya será el modelo indiscutible para la plástica contemporánea, apreciándose una mayor y más destacada presencia en los museos españoles. ${ }^{32}$

Fueron numerosas las referencias a la sala de Goya en la prensa y en los testimonios de los visitantes al museo a comienzos del siglo xx. El escritor Francisco Fernández Villegas, quien escribía bajo el pseudónimo de Zeda, afirmó en $1901:^{33}$

Ciertamente, penetrar en la sala de Goya de nuestro Museo Nacional es como asistir a la resurrección momentánea de la sociedad de fines del siglo XVIII y principios del siglo xıx. En esa sociedad puede decirse que el personaje reinante es la maja. Ella la protagonista de esa gran galería de cuadros creados por el genio del pintor aragonés. Las grandes damas muestransenos [sic] allí ataviadas con el traje de majas; de maja es la gallardía y el vestido de la Reina María Luisa; las majas llenan los cuadros que representan las fiestas populares, y majas hay también en el lúgubre lienzo que representa los fusilamientos de la Moncloa.

Entre estos testimonios también se encuentra el del pedagogo valenciano Félix Martí Alpera en la revista La Escuela Moderna, del año $1907 .{ }^{34}$ En ella escribió un artículo titulado «Los niños en el Museo del Prado», prestando es2012.

32. Javier Portús Pérez: El concepto de pintura española. Historia de un problema, Verbum, Madrid,

33. La Época, 31 de diciembre de 1901, p. 1.

34. La Escuela Moderna, V, 1907, p. 13. 
pecial atención a la sala de Goya, la única del museo en la que, según él, podían contemplarse niños representados con naturalidad.

$\mathrm{Al}$ igual que había sucedido con la sala de los cartones, la de 1898 fue referenciada en las guías de los viajeros extranjeros. Un aspecto interesante de su museografía es, según la guía Baedeker de 1908, un expositor giratorio en el que se mostraban los dibujos de Goya (fig. 3). ${ }^{35}$ Esta publicación alemana aporta nuevos datos e impresiones sobre esta sala: ${ }^{36}$

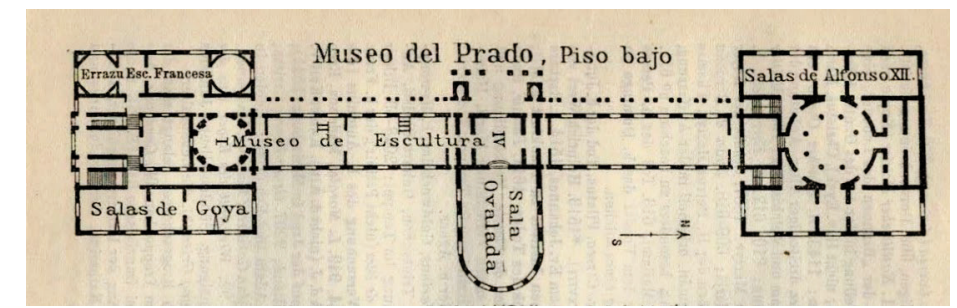

Fig. 3. Plano del Museo del Prado (piso bajo), 1908, Karl Baedeker: Espagne et Portugal. Manuel du Voyager, Karl Baedeker Editeur, Leipzig, 1908, p. 78

Sala de Goya, dividida en varios compartimentos. Esta sala no conserva, es cierto, ninguna de las obras maestras del gran realista (p. 74), ${ }^{37}$ pero vemos en ella interesantes cuadros decorativos con escenas de la vida popular en España, (modelos para los tapices del Escorial, p. 93) y composiciones fantásticas procedentes de su casa y montadas sobre lienzo.

Otra documentación que arroja información al respecto, son las fotografías del francés Joseph Lacoste y Borde conservadas en la colección de fotografía antigua del Museo, en las que se aprecia la disposición de las estancias en las que podían verse las obras de Goya a comienzos de la centuria (figs. 4 y 5 ). ${ }^{38} \mathrm{La}$ evolución de la museografía es reflejo del cambio de una transformación ideológica, con la colocación de La maja desnuda en la galería central del museo.

35. MAtilla y Portús: «Ni una pulgada de pared sin cubrir...», p. 98.

36. Karl Baedeker: Espagne et Portugal. Manuel du Voyager, Karl Baedeker Editeur, Leipzig, 1908, pp. 80 y 81 .

37. Remite a la página 74 en la que enumera los cuadros de Goya que en 1908 ocupaban la galería central del museo. En esa época se habían añadido a los expuestos en esta tribuna privilegiada La maja vestida y La maja desnuda, procedentes de la Real Academia de Bellas Artes de San Fernando y el retrato de los duques de Osuna. Ibidem, pp. 74 y 75.

38. Lacoste fue continuador del establecimiento de Laurent, tras la muerte de este y de su heredero Roswag. Fue nombrado fotógrafo del Museo del Prado por Real Orden en 1901. Las fotografías fueron ejecutadas antes de 1915, año en el que fue llamado a filas en su país natal y cesó en su actividad como fotógrafo. Una ficha detallada sobre su biografía fue escrita por Ana María V. Gutiérrez Martínez en la página web de la Real Academia de la Historia: Ana María V. Gutiérrez Martínez: «Joseph Jean Marie Lacoste y Borde», http://cort.as/-KCr2 (consultado el 15/2/2019). 
La sala de Goya mantuvo las obras que figuran en el proyecto de 1898, pero se introdujeron modificaciones en su ordenación que permitieron, entre otras cuestiones, excluir de la sala Los fusilamientos y La lucha con los mamelucos, que se mantuvieron en la galería central. Además, el expositor giratorio que menciona la guía Baedeker despareció, pues los dibujos pasaron a ser expuestos en vitrinas horizontales colgadas del muro.

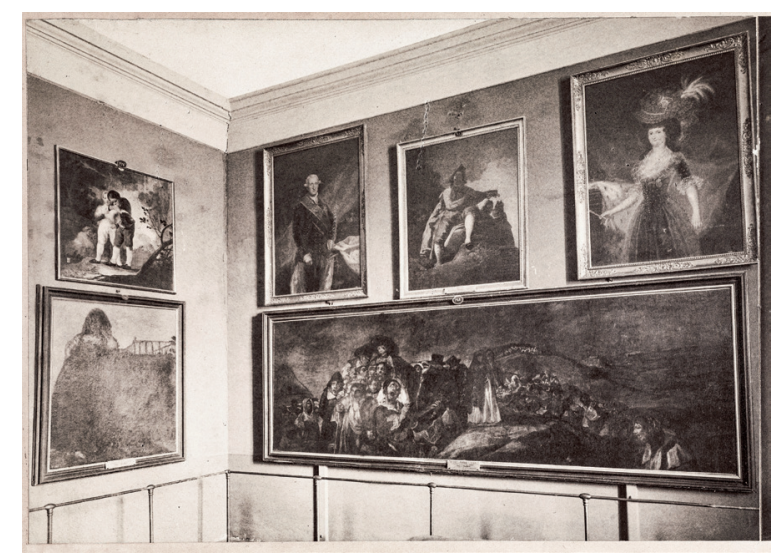

Fig. 4. Joseph Lacoste y Borde, Sala de Goya, 1907-1915, Museo Nacional del Prado

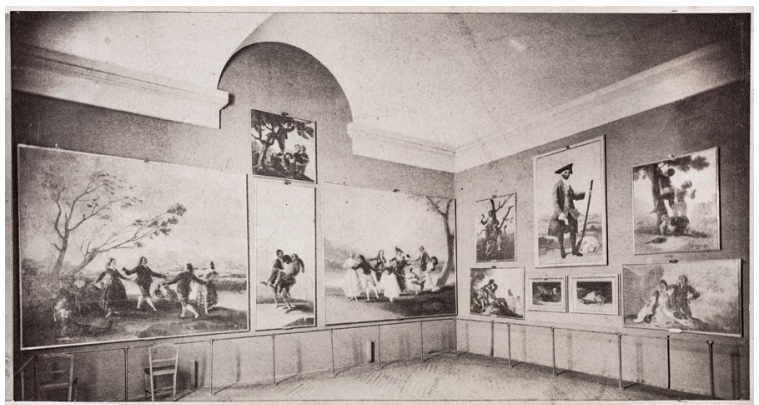

Fig. 5. Joseph Lacoste y Borde, Sala de Goya, 1907-1915, Museo Nacional del Prado

\section{La sala de Goya en el Museo de Valencia}

Si la creación de las salas de Goya en el Museo del Prado había obedecido a un deseo de privilegiar ciertos aspectos de la obra del pintor de Fuendetodos, la creación en 1910 de la estancia dedicada al artista en el Museo de Bellas Artes de Valencia se debió a la iniciativa de la Real Academia de Bellas Artes de San Carlos. 
La institución valenciana había atesorado desde principios del XIX obra de Goya y de sus coetáneos, tal es el caso del retrato de Joaquina Candado Ricarte, donado por la propietaria a la Real Academia de Bellas Artes de San Carlos en 1819. ${ }^{39}$ Tres años antes, Asensio Juliá, discípulo de Goya, había hecho entrega a la Academia de su obra El náufrago, pintada en $1815 .{ }^{40}$ Un siglo más tarde, la propia Academia demostró el valor que otorgaba a la pintura del maestro de Fuendetodos, creando en 1910 una sala dedicada a él en la antigua sede del Museo de Bellas Artes en el convento del Carmen (fig. 6). ${ }^{41}$ En el Acta de la Junta General de la Academia del 8 de noviembre de 1910 se señalaba:

Durante las vacaciones se dio gran impulso a la nueva sala de Goya la cual quedó terminada el día 19 del pasado octubre. [...] Para esta sala nuestro paisano el ilustre pintor D. Antonio Muñoz Degrain regaló un retrato de Goya copia hecha por el propio Sr. Muñoz Degrain, que pintó el insigne valenciano D. Vicente López, existente en el Museo de Arte Moderno de Madrid.

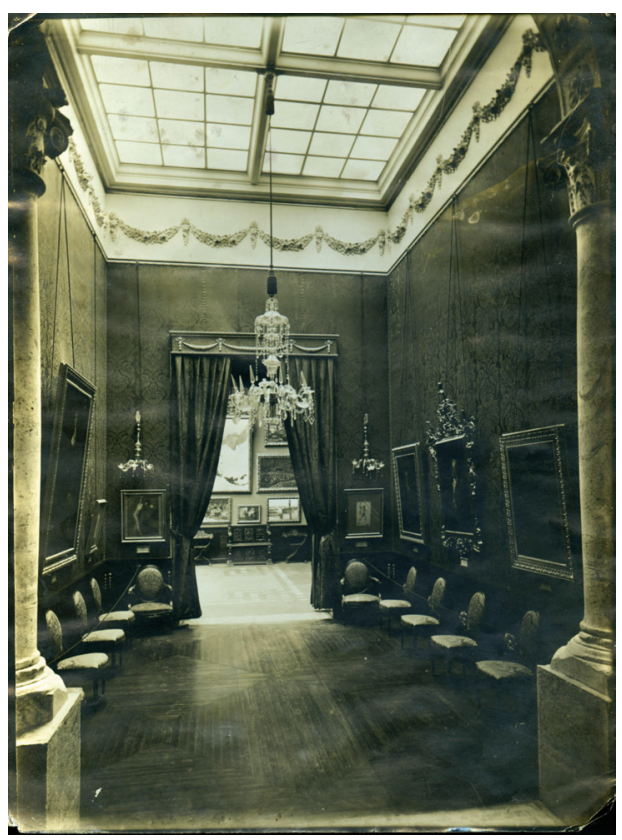

Fig. 6. Sala de Goya del Museo de Bellas Artes de Valencia, ca. 1910, Gentileza del Museo de Bellas Artes de Valencia

39. «Junta del 13 de junio de 1819». 1819. Inventario 1797-1849, n. ${ }^{\circ}$ 149. Archivo de la Real Academia de Bellas Artes de San Carlos de Valencia. [ARAscv]

40. «Junta del 11 de agosto de 1816». 1816. Inventario 1797-1849, n..$^{\circ} 144$. ARASCV.

41. Salvador Aldana Fernández: «Pintores valencianos del xix en algunas donaciones a la Real Academia de Bellas Artes de San Carlos», en Salvador Aldana Fernández: Pintura valenciana del siglo XIX, Real Academia de Bellas Artes de San Carlos de Valencia, Valencia, 2001, pp. 99-130. 
Es decir, en el caso de la sala valenciana se aprecia una colaboración del ambiente artístico de la ciudad, cuyos pintores fueron -siguiendo la estela de Vicente López-, fervientes partidarios del arte de Goya.

El diario valenciano Las Provincias, aporta datos de relevancia acerca de la génesis de esta sala. Durante las décadas anteriores, la colección artística de la Academia y del Museo de Bellas Artes fue creciendo de tal manera, que cuando el pintor Antonio Muñoz Degrain quiso realizar una valiosa donación de obras de arte al museo, este vio la necesidad de incrementar sus espacios de exhibición, a fin de dar cabida a sus nuevas colecciones. El planteamiento seguido por el centro fue el de crear salas monográficas dedicadas a los grandes autores de la pintura española y valenciana: ${ }^{42}$

Por esto la Academia de San Carlos trazó un programa para la ampliación del Museo Moderno, a base del sistema monográfico, si cabe la frase; es decir, construir nuevas salas especiales para un solo autor, y comenzó por rendir homenaje al gran Goya, $\tan$ brillantemente representado en el museo, construyendo la sala consagrada al primero de los maestros modernos del arte español. Los trabajos tocan a su fin. Según noticias, en breve se efectuará la inauguración de la sala Goya, sin duda la más espléndida dedicada a un solo artista en los Museos de España.

La noticia continúa describiendo cuál iba a ser la aportación personal de Antonio Muñoz Degrain a la configuración de dicha sala:

Nuestro paisano contribuye al homenaje rendido a Goya, regalando una copia del famoso retrato del autor de los «caprichos», pintado por el valenciano Don Vicente López. [...]

Pero hay algo aún más importante. Después de la sala de Goya se impone la de Muñoz Degrain. Ya está designado el emplazamiento, y a finales del próximo agosto llegará a Valencia nuestro paisano, ultimándose detalles relativos a la decoración, dimensiones y otros pormenores de la sala.

Es decir, la creación de la estancia se debió a la nutrida colección de la Academia y al impulso recibido por parte de Muñoz Degrain, admirador de la obra del pintor de Fuendetodos.

El mismo diario proporcionó información acerca de dicha sala una vez inaugurada. ${ }^{43}$ La organización de esta resulta de gran interés. En el artículo se indicaba que la sala «se ha construido de planta», de lo que se deduce la importancia que el Museo concedió a este espacio. También se señalaba que sería la primera de varias salas monográficas a construir en el edificio. Al contrario de lo que sucedía en el Prado, donde las salas no recibían un tratamiento individualizado, esta se ambientó reproduciendo «la habitación de una persona acaudalada de los últimos años del siglo XVIII, época de Goya».

42. Las Provincias, 18 de julio de 1910, p. 1.

43. Las Provincias, 24 de octubre de 1910, p. 4. 
La sala se encontraba emplazada en el lado izquierdo del antiguo salón de autores contemporáneos y a ella se accedía a través de una arcada de mármol renacentista. Las paredes se encontraban tapizadas de damasco valenciano de color verde, con decoración de granadas y palmas, procedente de los talleres locales de Bernabé Rosell. El conjunto se completaba con una sillería de nogal y un zócalo de la misma madera tallado dispuesto en los paramentos, coronados por un friso de guirnaldas. La luz natural penetraba en la sala gracias a una cubierta de cristal mate. Un amplio cortinaje comunicaba esta sala con la contigua, que se destinaría a la exposición de las obras de Muñoz Degrain.

La Guía del Museo de Bellas Artes de Valencia de 1915 incluía algunos datos relevantes. ${ }^{44}$ En ella se indicaba que las arañas y «lumbreras» antiguas eran de cristal veneciano y que el pórtico de mármol italiano procedía del antiguo palacio del Embajador Vich. ${ }^{45}$ La guía es más específica sobre las obras de Goya expuestas en la sala, y a las ya citadas añade una Figura masculina (dibujo al aguatinta) y Desnudo de hombre (dibujo a lápiz), así como un autógrafo del artista fechado en 1790, en el que agradece a la Academia de San Carlos el haberle nombrado miembro de honor.

El artículo informaba finalmente de cómo se encontraban expuestas las obras del pintor aragonés. Se trataba de cuatro lienzos: el retrato de Joaquina Coronado, el de Bayeu, el del grabador Esteve y el de Mariano Ferrer y Aulet, secretario de la Academia. Todos ellos se exponían «colocados en marcos de talla antigua valenciana y colgados por medio de cordones de seda». A estos había que añadir la copia que Muñoz Degrain hizo del retrato de Vicente López y una colección de dibujos de Goya. La sala fue inaugurada por Alfonso XIII y Victoria Eugenia, para los que se dispuso un dosel en el gran salón del museo.

Una década más tarde, el artista valenciano Ismael Blat Monzó (1901-1976) ejecutó un óleo en el que representó el interior de esta sala, posiblemente fruto de un ejercicio de aprendizaje durante su etapa formativa en la escuela dependiente de la Real Academia de San Carlos. ${ }^{46}$ En él se aprecian todos los elementos anteriormente descritos.

Así, quedaba configurada, en la institución artística más importante de la ciudad, una sala consagrada a Francisco de Goya, figura que funcionaba de vínculo entre las colecciones antiguas de pintura valenciana y española y las de arte contemporáneo.

44. vv. AA., Guía del Museo de Bellas Artes de Valencia, Museo de Valencia, Valencia, 1915, pp. 54 y 55.

45. Dicho pórtico se conserva en la actualidad en el Museo de Valencia. A mediados del siglo xix el palacio había sido derribado y, por iniciativa de los académicos de San Carlos, una parte de sus mármoles se trasladaron al convento del Carmen. En 2006 fue inaugurada la reconstrucción del patio en la sede del Museo de Bellas Artes de Valencia en la sede de San Pío V. Para más información sobre el monumento: SALVAdOR Vila FerRer: «La recuperación del patio del palacio del Embajador Vich», en Loggia, Arquitectura E Restauración, Universidad Politécnica de Valencia, Valencia, 2001, pp. 44-51.

46. Forma parte de la colección del Museo de Bellas Artes de Valencia. Se trata de una obra de gran formato (129,5 × 88,4 cm). Figuró en el catálogo de la exposición: Orígenes del Museo de Bellas Artes de Valencia: Ramón Martínez Miñana (comisario): Orígenes del Museo de Bellas Artes de Valencia. 175 aniversario, Generalitat Valenciana, Valencia, 2015, pp. 62 y 63. 


\section{La sala de Goya del Museo de Zaragoza}

Otro de los centros pioneros en la disposición de una sala monográfica dedicada al arte de Goya fue el Museo de Zaragoza, antiguo Museo Provincial. En este caso, la iniciativa no vino de la propia institución, sino del ambiente cultural del regionalismo aragonés, encabezado por intelectuales deseosos de hacer de Goya un modelo para los jóvenes artistas locales. ${ }^{47}$

En 1907, en vísperas de la celebración de la Exposición Hispano-Francesa del año siguiente, el crítico José Valenzuela la Rosa planteó la posibilidad de crear de una sala dedicada a Goya en la nueva sede del Museo Provincial que se había construido con motivo de la muestra. Propuso que Zaragoza se convirtiese en la «meca del goyismo»: ${ }^{48}$

Un Museo, en la patria del gran artista de Fuendetodos, sin ningún cuadro de este, es un contrasentido, mejor dicho, es una irreverencia. Goya debe ser nuestro ídolo, el objeto de nuestra admiración más ferviente. Cuando su fama se va extendiendo por todo el globo y cuando los artistas del mundo entero vuelven sus ojos hacia él considerándolo como un genio precursor de las nuevas corrientes, es muy justo que hagamos de Zaragoza la Meca del goyismo.

En 1908 se inauguraba el Palacio de Bellas Artes de la exposición con una sala dedicada a Goya, a modo de transición entre las secciones de arte retrospectivo y moderno, al igual que sucedió en Valencia dos años más tarde.

Entre las obras expuestas se encontraban los bocetos para los techos del Pilar (propiedad del Cabildo Metropolitano de Zaragoza), los retratos del duque de San Carlos y de Fernando VII (procedentes de la Junta del Canal Imperial), el retrato del marqués de San Adrián, el del arzobispo Joaquín Company (de la galería de retratos del Palacio Arzobispal de la ciudad), el autorretrato de Goya (de la Escuela de Bellas Artes de Zaragoza) o tres retratos más de dudosa autoría catalogados como «época y estilo Goya». Otra de las obras expuestas fue un boceto para uno de los cartones para tapices, Baile a orillas del Manzanares.

El catálogo de la sección de arte retrospectivo de la exposición nos aporta más información acerca de las noventa obras expuestas en esta sala. ${ }^{49}$ Entre

47. Alberto Castán Chocarro dedicó su tesis doctoral y numerosos estudios a la investigación del regionalismo pictórico aragonés y del ambiente cultural zaragozano a comienzos del siglo xx. Alberto CASTÁN Chocarro: Señas de identidad. Pintura y regionalismo en Aragón (1898-1939), Institución Fernando el Católico, Zaragoza, 2016.

48. Revista Aragonesa, V, 1907, pp. 112-114. El nuevo edificio del Museo Provincial de Zaragoza fue obra del arquitecto municipal Ricardo Magdalena Tabuenca, con la colaboración de Julio Bravo Folch. Frente al estilo mucho más arriesgado de los pabellones de arquitectura efímera, el museo constituye una revisión de la arquitectura civil aragonesa de los siglos XVI y XVII, incurriendo en un historicismo que se consideró mucho más adecuado para albergar las colecciones de Bellas Artes y de Arqueología. AsCENSIÓN Hernández Martínez: Magdalena, Navarro, Mercadal, Caja de Ahorros de la Inmaculada de Aragón, Zaragoza, 1999, pp. 35-43.

49. vv. AA., Catálogo de la sección de Arte Retrospectivo, Tipografía de Emilio Casañal, Zaragoza, 1908, pp. 102-106. 
ellas figuraban cuatro tablas: una capea, El aquelarre o Fiesta de brujos, Procesión de disciplinantes y Tribunal del Santo Oficio, propiedad todas ellas de la baronesa de Areyzaga. Entre otros bocetos de pinturas para las bóvedas del Pilar se encontraban tres de Antonio González Velázquez, once de Francisco Bayeu y diecinueve de Ramón Bayeu. El general Antonio de Mazarredo contribuyó con varios cuadros considerados obra de Goya, posteriormente cuestionados en su autoría. Completaba el conjunto un temprano autorretrato de Goya procedente de la Escuela de Artes y Oficios de la ciudad. ${ }^{50}$

Conocemos bien la disposición de la sala, así como las obras allí expuestas, gracias a las fotografías realizadas por Coyne de los salones de la Exposición Hispano-Francesa (fig. 7). La sala contaba también con tres vitrinas en las que se exhibieron objetos litúrgicos de diferentes épocas, en su mayor parte dalmáticas, casullas y estandartes.

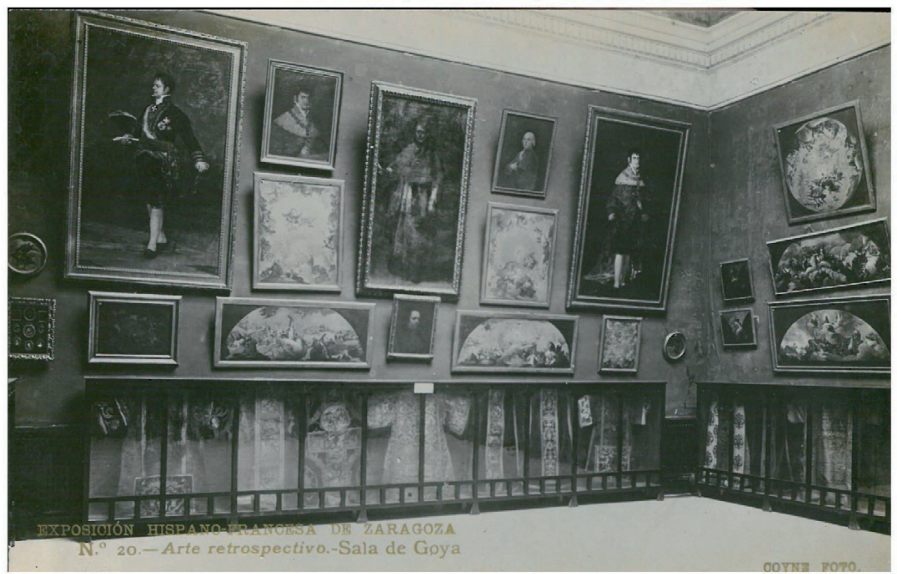

Fig. 7. Estudio Coyne, Sala de Goya en el Palacio de Bellas Artes de la exposición Hispano-Francesa de Zaragoza, 1908, Colección particular

En realidad, la creación de esta sala en el Palacio de Bellas Artes de la exposición, respondía a dos motivaciones. La primera, como se ha señalado antes, sería la de ofrecer un espacio de transición entre las secciones de arte retrospectivo y arte moderno. La segunda, recrear espacios ambientados en la época de los Sitios (1808-1809), lo que llevó a colocar al pie de la escalera principal una berlina de estilo rococó que había pertenecido al marqués de San Adrián.

50. Actualmente propiedad de Ibercaja. El marqués de Zurgena poseía otra copia de este retrato, y cuando Mariano de Ena vendió su colección en 1947, adquirió también el original en 1955. Lo heredó la marquesa de Solana y posteriormente los condes de Elda, que fueron quienes lo vendieron a Ibercaja en 1997. Todos estos datos fueron recogidos en: FrÉDERIC JiMÉNO: «La obra de Goya conservada en Aragón. A propósito de dos centenarios (1908-1928)», en JuAn CARLos Lozano López (comisario): La memoria de Goya (1828-1978), Fundación Goya en Aragón, Zaragoza, 2008, p. 10. p. 13. 
Al igual que el retrato que Goya hizo de su propietario y que también fue expuesto en esta muestra, llegó desde Tudela.

Concluida la exposición, la sala siguió estando dedicada al maestro aragonés dentro del nuevo uso museístico del edificio. Sin embargo, habría que esperar unos años hasta que se abriese al público. Entre 1808 y 1815 el museo se dedicó a decorar este espacio, además de gestionar el depósito de algunas de las obras que se habían expuesto en ella durante la Exposición Hispano-Francesa. Los trabajos de adecuación de la sala fueron supervisados por los miembros de la Academia de Nobles y Bellas Artes de San Luis de Zaragoza, una institución siempre cercana al museo. Así, se acordó crear una reja de hierro para cerrar y asegurar la sala. En 1913, Luis de Lafiguera, arquitecto y profesor de la Escuela de Artes y Oficios de la ciudad, presentaba en la Academia un proyecto de verja que fue acogido con buena aceptación..$^{51}$ En el mes de noviembre de ese año, Francisco Marín Bagüés, conservador del museo, comunicaba a la Academia las labores realizadas para la instalación de esta sala. Durante esos meses, la Academia estimó que «existiendo en la Escuela de Industrias y Bellas Artes algunos apuntes de Bayeu y Larraz y otros notables artistas, debiera solicitarse de la dirección de aquel centro que, al donativo del autorretrato de Goya, sumase el de los trabajos citados». Mariano de Pano, miembro de la Academia, también dio su opinión al respecto, afirmando que lo adecuado sería que en la misma sala quedasen recogidas las obras de los artistas que precedieron y siguieron al maestro. ${ }^{52}$ En diciembre se encargaba a Francisco Marín Bagüés que se encargase del ornato de este espacio. ${ }^{53}$ Este pintor expondría posteriormente una interesante idea: hacer coincidir la inauguración de la sala con una exposición dedicada al artista de Fuendetodos, de tal manera que luego los expositores cediesen sus obras en depósito al museo, pudiendo crear así una verdadera sala de Goya. ${ }^{54}$ Finalmente, la sala fue inaugurada con las obras ya existentes en la colección del museo además de las procedentes de un depósito en 1915 de la Escuela de Artes y Oficios: el autorretrato de Goya, otra cabeza al óleo atribuida al mismo artista y un autógrafo del pintor. ${ }^{55}$

El resultado fue el de una estancia más austera, alejada del horror vacui de la sala de 1908. En mitad de la sala se dispuso un busto de Goya realizado en yeso por Mariano Benlliure Gil. Así lo reproducen las imágenes realizadas por José Galiay Sarañana, conservadas en el Archivo Histórico Provincial de Zaragoza

51. «Junta del 9-III-1913». 1913. Libro de Actas 1903-1914. Archivo de la Real Academia de Bellas Artes de San Luis de Zaragoza [ARANBSL]. Los trabajos fueron llevados a cabo en los talleres del Hospicio Provincial. Algunos elementos decorativos fueron traídos de Barcelona. Agradezco a Wifredo Rincón García su amabilidad al facilitarme el acceso al Archivo de la Real Academia de Bellas Artes de San Luis, durante el mes de diciembre de 2018.

52. «Junta del 16-XI-1913». 1913. Libro de Actas 1903-1914. ARANBSL.

53. «Junta del 14-XII-1913». 1913. Libro de Actas 1903-1914. ARANBSL.

54. «Junta del 8-II-1914». 1914. Libro de Actas 1903-1914. ARANBSL.

55. «Junta del 21-XI-1915». Libro de Actas 1903-1914. ARANBSL. En septiembre de 1916 era publicado un reportaje sobre el Museo Provincial de Zaragoza en La Esfera, en el que ya se cita el autorretrato de Goya como parte de la sala dedicada al artista: La Esfera, 23 de septiembre de 1916, pp. 12 y 13. 
(fig. 8) ${ }^{56}$ El conjunto quedaría completado con la reja historicista que confirió al espacio un carácter más solemne.

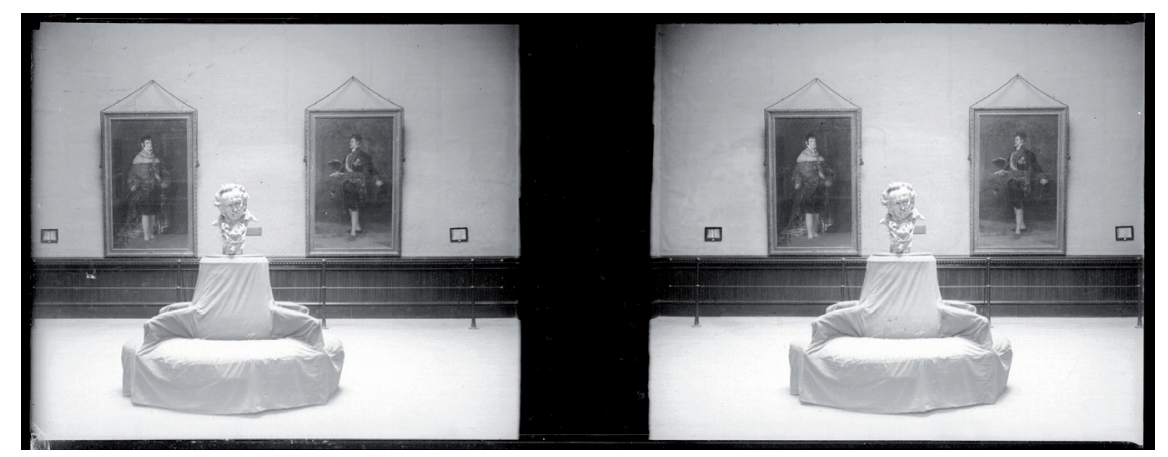

Fig. 8. José Galiay Sarañana, Sala de Goya en el Museo Provincial de Zaragoza, Archivo Histórico Provincial de Zaragoza

La culminación del largo proceso de creación de esta sala, desde su antecesora en la Exposición Hispano-Francesa hasta su apertura en 1915, coincidió con un momento cumbre en la reivindicación de la figura de Goya en Aragón. En ese mismo año, Ignacio Zuloaga firmaba las escrituras de la casa natal del pintor en Fuendetodos, adquiriendo la propiedad e impulsando la creación de unas escuelas municipales para el pueblo. ${ }^{57}$ Dos años, se había organizado una fiesta goyesca para recaudar fondos con este objetivo y se había colocado una lápida conmemorativa esculpida por el profesor de la Escuela de Artes y Oficios Dionisio Lasauén. ${ }^{58}$

Tanto la Academia como la dirección del museo continuaron en su empeño de conseguir nuevas obras para dicha sala, y en 1921 entraban en depósito de la Junta del Canal Imperial de Aragón los retratos de Fernando VII y del duque de San Carlos que pudieron verse durante la exposición de $1908 .{ }^{59}$

\section{A MODO DE CONCLUSIÓN}

Las cuatro décadas que aborda este estudio (1875-1915) constituyeron un periodo clave en el afianzamiento del personaje de Francisco de Goya como el artista «más español», tal y como expresaron algunos miembros de la intelec-

56. Archivo Histórico Provincial de Zaragoza. Número de referencia: ES/AHPZ - MF/GALIAY/001390.

57. Para más información sobre la relación entre el pintor vasco y la localidad natal de Goya: vV. AA.: Zuloaga en Fuendetodos, Diputación de Zaragoza, Consorcio Goya Fuendetodos, Zaragoza, 1996.

58. CASTÁN: Señas de identidad..., pp. 206 y 207.

59. JiMÉNO: «La obra de Goya conservada en Aragón...», p. 13. 
tualidad del momento. En dicho proceso, un paso importante fue la aparición de salas dedicadas monográficamente al artista. En el caso del Prado, estas salas fueron el resultado de unos criterios museográficos en consonancia con la situación política y, por ende, del deseo de seleccionar ciertas facetas de la producción de Goya. En el del Museo de Bellas Artes de Valencia y en el caso zaragozano, la creación de sus salas de Goya se debió al impulso de sus respectivas Academias y la predilección de sus artistas locales por el maestro de Fuendetodos, a lo que habría que sumar el ambiente del regionalismo cultural aragonés en la sala de Zaragoza.

Como consecuencia de estos criterios museográficos, además de otras circunstancias relacionadas con el gusto de la época, las últimas décadas del siglo XIX y las primeras del xx fueron las más prolijas en homenajes artísticos e institucionales dedicados a Goya, lo que culminaría en 1928 con la celebración del centenario de su fallecimiento y la apertura de nuevas salas de Goya en otros museos e instituciones. ${ }^{60}$

\section{BibLIOGRAFÍA}

Aldana Fernández, Salvador: «Pintores valencianos del XIX en algunas donaciones a la Real Academia de Bellas Artes de San Carlos», en Salvador Aldana Fernández: Pintura valenciana del siglo XIX, Real Academia de Bellas Artes de San Carlos de Valencia, Valencia, 2001, pp. 99-130.

Araujo Sánchez, Ceferino: Goya y su época, La España Moderna, Madrid, 1896.

-: Los Museos de España, Imprenta de Medina y Navarro, Madrid, 1875, pp. 85 y 86.

BAedeker, Karl: Espagne et Portugal. Manuel du Voyager, Karl Baedeker Editeur, Leipzig, 1908, pp. 80 y 81.

Beroqui Martínez, Pedro: El Museo del Prado (Notas para su historia), Gráficas Marinas, Madrid, 1933, p. 102

Calvo Serraller, Francisco: La invención del arte español, Galaxia Gutenberg, Madrid, 2013.

Castán Chocarro, Alberto: Señas de identidad. Pintura y regionalismo en Aragón (18981939), Institución Fernando el Católico, Zaragoza, 2016.

De Madrazo, Pedro: Catálogo de los cuadros del Museo del Prado de Madrid, Museo Nacional del Prado, Madrid, 1873, p. XIII.

-: Catálogo de los cuadros del Museo del Prado de Madrid, Museo Nacional del Prado, Madrid, 1882, pp. 435-438.

Fournel, François-Victor: Aux pays du soleil. Un été en Espagne. A travers l'Italie. Alexandrie et le Caire, A. Mame et fils, Tours, 1883, p. 54.

GÉAL, Pierre: «El salón de la Reina Isabel en el Museo del Prado (1853-1899)», en Boletín del Museo del Prado, Museo Nacional del Prado, Madrid, 2001, pp. 143-172.

JimÉnO, FrÉDERIC: «La obra de Goya conservada en Aragón. A propósito de dos centenarios (1908-1928)», en JuAn Carlos Lozano López (comisario): La memoria de Goya (18281978), Fundación Goya en Aragón, Zaragoza, 2008, p. 13, p. 10.

60. Dicho aniversario ya ha merecido varias investigaciones, entre las que destaco: vv. AA.: Catorce visiones en torno a Goya: publicaciones de la «Junta del Centenario de Goya», 1926-1928, Diputación General de Aragón, Departamento de Educación y Cultura, Zaragoza, 1996. 
Kerr-Lawson, E.: A catalogue of the paintings in the Museo del Prado at Madrid, William Heinemann London, 1896.

Matilla Rodríguez, José Manuel y Portús Pérez, Javier (eds.): El grafoscopio. Un siglo de miradas al Museo del Prado (1819-1920), Museo Nacional del Prado, Madrid, 2004, p. 8398.

Peiró Martín, Ignacio: En los altares de la patria. La construcción de la cultura nacional española, Akal, Madrid, 2017.

Portús Pérez, Javier: «La nacionalización del Prado, 1868-1898. Un museo para los pintores», en vv. AA.: Museo del Prado: 1819-2019. Un lugar de memoria, Museo Nacional del Prado, Madrid, 2018, pp. 70-107.

-: El concepto de pintura española. Historia de un problema, Verbum, Madrid, 2012.

Martínez Miñana, Ramón (COmisario): Orígenes del Museo de Bellas Artes de Valencia. 175 aniversario, Generalitat Valenciana, Valencia, 2015, pp. 62 y 63.

Vega González, Jesusa y Vidal Rivas, Julián: «El devenir de la Historia del Arte, sus prácticas y sus consecuencias: el caso de Francisco de Goya», en Luis ArCiniEgA GARCía (coor.): Memoria y significado: uso y recepción de los vestigios del pasado, Universidad de Valencia, Valencia, 2013, pp. 341-422.

-: Pasado y Tradición. La construcción visual del imaginario español en el siglo XIX, Editorial Polifemo, Madrid, 2016.

Vila Ferrer, Salvador: «La recuperación del patio del palacio del Embajador Vich», en Loggia, Arquitectura E Restauración, Universidad Politécnica de Valencia, Valencia, 2001, pp. 44-51.

vv. AA., Catálogo de la sección de Arte Retrospectivo, Tipografía de Emilio Casañal, Zaragoza, 1908, pp. 102-106.

vv. AA.: Catorce visiones en torno a Goya: publicaciones de la «Junta del Centenario de Goya», 1926-1928, Diputación General de Aragón, Departamento de Educación y Cultura, Zaragoza, 1996.

vv. AA., Guía del Museo de Bellas Artes de Valencia, Museo de Valencia, Valencia, 1915, pp. 54 y 55.

Yriarte, Charles: Goya, H. Plon, París, 1867, p. 131. 